IOS Press

\title{
An exploratory study of how undergraduate students use official statistics as a source of information for their academic assignments
}

\author{
José Luis Ángel Rodríguez Silva* and Mario Sánchez Aguilar \\ ${ }^{a}$ Universidad Politécnica de Aguascalientes, Mexico \\ ${ }^{\mathrm{b}}$ Instituto Politécnico Nacional, CICATA Legaria, Programa de Matemática Educativa, Mexico
}

\begin{abstract}
The official statistics generated by government offices and ministries are fundamental to guide actions in the decisionmaking process within a country. For example, official statistics could be used to promote and allocate public goods like local, regional and national budgets. Moreover, due to the high quality standard required to generate official data, such information is ideal to promote a better understanding about the important facts in economic, sociodemographic, geographic, environmental and governmental management issues. However, it has been observed that many undergraduate students do not use such data in an extensive manner, and they reveal limitations in accessing, analyzing and extrapolating such information to their benefit, both in academic and personal settings. The aim of this work is to describe to what extent Mexican undergraduate students use official statistics as part of their academic assignments, and to identify the main obstacles they encounter when trying to access and use official statistics.
\end{abstract}

Keywords: Official statistics, undergraduate students, information usage, exploratory study

\section{Introduction}

Modern statistics have their ancient roots in the analysis of state data, which is information provided from public life such as birth and death rates, unemployment rates, farm taxes values, environmental statistics, etc. Indeed, official statistics play a prominent role in guiding government decisions; decisions taken in citizens' private lives are also guided by official data (e.g. inflation rates are fundamental to making better and more rational decisions in domestic economic affairs). In this sense, official statistics are considered a key element in order to understand the main economic and sociodemographic phenomena of a nation, and thus official statistics can be considered to be the most detailed account of the important facts of a nation.

\footnotetext{
* Corresponding author: José Luis Ángel Rodríguez Silva, Solandra No. 108, Fracc. Yalta Campestre, C.P. 20926, Jesús María, Aguascalientes, México. Tel.: +52 449910 5300, Ext. 7378; +52 449 323 9937; E-mail: jlangel2010@ hotmail.com.
}

Due to the importance of official statistics, almost all countries have promoted the creation and development of National Statistical Offices (NSOs). Although such offices are government agencies in charge of gathering and analyzing official data, other national ministries might also gather their own information to fit their own needs. The NSO is important not only in gathering and supplying data to society, but also in showing the easiest ways of using official information among population segments, including of course academia. University students and teachers are natural users of official data because their research and academic projects frequently use this information to provide a proper framework for the work. Unfortunately, it has been observed that students and even university teachers usually do not have sufficient skills to locate, select and use the required information [1]. This phenomenon can perhaps be explained by the inherent complexity of official statistics, because the NSO frequently runs several projects, so the data produced may be difficult to lo- 
cate. But this is not the only obstacle to the proper use of official information: in some cases the analysts effectively locate the information, but then use it in an inadequate way, for example by not considering the sampling statistical properties of a multistage design of a survey.

Using this background, we can now enunciate the main objectives of the study reported in this manuscript:

(1) To know to what extent undergraduate Mexican students use official information as an aid to support their academic projects and assignments, and

(2) To know how easy it is for them to access and use such data and the type of information most frequently consulted.

With this study we expand our knowledge on the barriers or obstacles that undergraduate students may encounter when trying to make use of official statistics as part of their school assignments, and try to promote the use of official statistics in this sector of society.

The manuscript is structured as follows: we will begin with a brief review of the origin and status of official statistics in Mexico, then we will present a review of literature relevant to the study. Next we describe the method followed to gather and analyze field information; after this we present the results of the data analysis. Finally we discuss the main findings and provide suggestions on how to promote a more widespread use of official data.

\section{On the status of official statistics in Mexico}

National Statistical Offices (NSOs) are government agencies in charge of gathering and analyzing official data. In the case of Mexico, where this study was developed, the NSO is the National Institute of Statistics and Geography (INEGI, by its Spanish acronym).

Due to constitutional reforms in articles XXVI and XXIX-D of the Mexican Political Constitution, in 2008 the National System of Statistical and Geographic Information (NSSGI) was created; one of its objectives is to promote among the population the use of official statistical and geographic information generated by the different government offices. The NSSGI itself is coordinated by INEGI, which has technical, administrative and management autonomy (and it is one of the very few NSOs in the world to have such status, carrying out surveys not only in statistics but also in geographic issues). INEGI has performed several actions to promote the use and dissemination of official statis- tics, such as intensive radio and TV spots, promotion among universities through invited lectures, etc.

To illustrate this kind of popularization initiative, INEGI promoted the writing of a book [2] entitled "What the indicators indicate" ("Lo que indican los indicadores", in Spanish) to explain several economic indicators; in addition, it has developed several electronic games aimed at children in order to illustrate several statistical or geographic facts about the country [3]. As an additional example, INEGI has promoted to increase the statistical skills of some of its employees by promoting a Master of Science in Official Statistics in combination with the Mathematical Research Center of Mexico (CIMAT, by its Spanish acronym), with the goal of increasing the quality and quantity of projects, a situation that could benefit the end users of official information.

However, these actions have proved not to be enough to impact wider segments of Mexican society. This is particularly true for statistics students and teachers at the undergraduate level. We have noticed through our own teaching experience that several undergraduate students and teachers have not developed the appropriate skills to properly use the vast set of official statistical information provided by INEGI and other government offices in Mexico.

From a nation's point of view, the non-use or misuse of official statistics is illogical because is very common that high-scale projects (like a national census or very demanding surveys) are quite expensive, and their costs are supported by society itself. Therefore, if societies do not use such information, an inefficient operability framework is created. Equivalently, the high cost of producing official data makes it absurd not to use it to promote better life standards. This situation is one of the reasons we developed this study, in which we identify some of the difficulties faced by undergraduate students in Mexico when trying to locate and use official statistics as part of their studies (descriptive summaries and databases, both located on the INEGI website). It is important to mention that the student sample was extracted from the city of Aguascalientes, where INEGI has its headquarters, and thus the students may be more familiar with INEGI; however, in the experience of the authors of this article, this effect would be minimal because INEGI has a national infrastructure and a permanent presence on the news radio, TV and social networks - so this effect was not taken into consideration in this study. 


\section{Review of the literature}

Several authors have pointed out the importance of the correct use of statistical data in order to guide certain aspects of the everyday decision-making process. For example, Moore and Notz [4] have noted that there is a widespread misunderstanding about how to interpret statistical data. Paulos [5] goes further by remarking on several undesirable consequences of being statistically illiterate even in day-to-day settings. In [6] it is shown that statistics is crucial for creating a reference framework to support well-informed decision processes, for example in the exchange of information between physicians and patients; in [7] we can find three examples of the importance of having basic capabilities in legal situations. In other words, it has been well established in the literature that there are important consequences of being statistically illiterate in academic, professional and daily contexts.

Moreover, the importance of cooperation between statisticians and academics has been recognized. For example, [8] mentions the importance of having (at minimum) statistical literacy and the fundamental role to be played by statisticians. Another example can be found in [9], which presents the successful cooperation between official and academic statisticians in the development of a statistical seasonal adjustment project. Finally, in the Mexican context, there is at least one successful official-academic statistics project, integrated by INEGI and CIMAT: a cooperative Master of Science (MSc) project. Since 2007, several INEGI employees have developed projects involving the application of academic statistics to official applications. For example, [10] documents the summary of an MSc thesis to provide a better fitting of the right-tail income distribution based upon a particular data set from a survey applied by INEGI, the National Survey of Incomes and Expenditures in Households in Mexico (ENIGH, by its Spanish acronym). More comments about the benefits of the interaction between academics and official statistics, particularly in some unexploited areas of such interaction, are presented in [11].

It has further been discussed in literature the importance of having students with sufficient skills to use official data, to exploit its capabilities and recognize its limitations. For example, [12] mentions the benefits of having well-trained students who can use official information and the role to be played by the NSO in the pursuit of this goal. In [13], some consequences about the learning of official statistics by using the Internet are explored. [14] sets out particular academic prob- lems produced by using official statistics in some specialized subjects like sociology. However, despite the often-claimed and sustained importance of students using official statistics, there is acknowledgment of the existence of a pedagogical problem associated with students' use of official statistics.

\section{Method}

To develop the study we invited several students from the eight most eminent public and private universities in the city of Aguascalientes, Mexico, i.e., the sampled population was defined as students from universities of Aguascalientes. We chose this city because it is where the first author of this article lives and works as statistics teacher, which facilitated access to local universities and their students. The specific sample of universities was divided as follows:

- Public: Autonomous University of Aguascalientes (UAA), Aguascalientes Institute of Technology (ITA), Polytechnic University (UPA) and Technologic University (UTA).

- Private: Monterrey Institute of Technology (ITESM), University of the Mexican Valley (UVM), Pan-American University (UP) and Cuauhtémoc University (UC).

Table 1 shows the different samples used in this study (these sample sizes show such figures by the feasibility of the application of the questionnaires). The numbers of selected students are given in the second column, the number of bachelor students in the third column, and their average age is included in the fourth column. It is important to mention that in Aguascalientes there are 10 public universities and 27 private universities.

We designed a questionnaire to be applied to a random sample of students from these universities. The design of the questionnaire is presented in the next section.

\subsection{Questionnaire design}

The questionnaire (see Appendix) was designed to gather information about the students' habits, attitudes and confidence about official information and the use thereof. Due to the fact that the main official statistical bureau in Mexico is INEGI, several questions are around the perceptions of students about the Mexican NSO. Finally, although we acknowledge that the questionnaire does not cover all the possible problems that 
Table 1

Universities participating in the study, number of students selected, number of bachelor students and students' average age

\begin{tabular}{|c|c|c|c|c|}
\hline Type & Institution name & Number of students & Number of bachelor students & Average age \\
\hline \multirow[t]{4}{*}{ Public } & Autonomous University of Aguascalientes (UAA) & 115 & 14,513 & 20.1 \\
\hline & Aguascalientes Institute of Technology (ITA) & 133 & 6,410 & 19.8 \\
\hline & Aguascalientes Polytechnic University (UPA) & 113 & 2,352 & 20 \\
\hline & Aguascalientes Technologic University (UTA) & 121 & 1,146 & 20.2 \\
\hline \multirow[t]{4}{*}{ Private } & Monterrey Institute of Technology (ITESM) & 111 & 1,113 & 20.6 \\
\hline & University of the Mexican Valley (UVM) & 125 & 752 & 21.2 \\
\hline & Pan-American University (UP) & 130 & 1,279 & 20.4 \\
\hline & Cuauhtémoc University (UC) & 118 & 3,142 & 20.7 \\
\hline
\end{tabular}

could arise from the use - or misuse - of official statistics, we decided to have a shorter questionnaire in order to avoid a non-response problem due to excessive length.

\subsection{Statistical sample design}

The questionnaires were administered during one week, from Monday to Friday, dividing the implementation of the questionnaires into three sessions, each with the same number of participating students (e.g. the 117 questionnaires administered to UAA students were divided into three sets, each one of $117 / 3=$ 39 students), at 10:00, 12:00 and 14:00. This procedure was followed to minimize error bias from "morning" against "afternoon" students (which in some cases could imply, because of their working activities, some kind of bias. In our case, it was proved that this fact did not influence the results, i.e., there is no significant difference between "morning" and "afternoon" students). However, one limitation of this study is that "night" or "Saturday" students were not selected in our study, simply because we consider that due to the reduced number of such kind of students, their perceptions could not have a significant impact in the results.

Natural clusters are: the universities themselves, morning vs afternoon vs night students, undergraduate vs graduate students, and female vs male students. In bachelor degrees, clusters include the year of study (freshman, sophomore, junior and senior), private vs public and finally (without trying to be absolutely comprehensive) "hard sciences" (like engineering) vs humanistic studies. As we will see in the results section, between these strata, we did not observe significant differences among these groups, and the perceived perception was related rather with the sub-dimensions of the use of official information itself, like the credibility of the NSO or the ease of use of the information on the website. Moreover, the sampling was not restricted to one particular career. Student participation was voluntary.
With these elements, we consider that despite the limitations of any sample design, the one that is proposed could contribute to understanding the problem of the use of official information by students.

We take as the pivotal variable question number 5, i.e., whether students have consulted the INEGI website at least once during the last six months. By applying a pilot survey to 100 students (50 students from UAA, a public university, and 50 students from ITESM, a private educational institution), we found the following: around $47 \%$ of respondents answered that they haven't consulted the INEGI website, whereas the remaining $53 \%$ of students answered that they have visited the INEGI Internet site. We applied the following expression for the minimum sample determination: $n=\left(z_{\alpha}^{2} p q\right) / \varepsilon^{2}$, where we considered the following values: the significance level $\alpha$ was fixed at 0.05 (i.e. we considered the experiment to have a $95 \%$ significance level); $p$ and $q$ the success and failure proportions respectively, were 0.5 (by the pilot findings and also in order to maximize the value of the sample size), and the estimation error $\varepsilon$ was equal to 0.05 .

\section{Results}

Table 2 contains some of the main results derived from the analysis of the answers to the questionnaires.

There are some interesting facts to note:

- Students in general do not extensively use government (official) information, due perhaps to the fact they do not regularly visit the official websites.

- Most of the students use official government information in assignments related to economic, financial or research matters. That is, despite the existence of engineering information (like construction or energy data), it seems that, for the most part, the information used is of an economicfinancial nature. 
Table 2

Students' answers to questionnaire items

\begin{tabular}{cl}
\hline Item & Students' answers \\
\hline 1 & Most frequent: 2 (676 cases $=70 \%)$ \\
& Second most frequent: $1(203$ cases $=21 \%)$ \\
& Third most frequent: $0(48$ cases $=5 \%)$ \\
2 & Most frequent: Economics $(609$ cases $=63 \%)$ \\
& Second most frequent: Finance $(164$ cases $=17 \%)$ \\
& Third most frequent: Research methods $(77$ cases $=$ \\
& $8 \%)$ \\
3 & Most frequent: Android apps $(802$ cases $=83 \%)$ \\
& Second most frequent: Internet $(145$ cases $=15 \%)$ \\
& Third most frequent: Specialized consulting centers \\
& (10 cases $=1 \%)$ \\
& Most frequent: INEGI (372 cases $=55 \%)$ \\
& Second most frequent: Ministry of Economy $(155$ \\
& cases $=23 \%)$ \\
& Third most frequent: Labor and Social Welfare $(81$ \\
& cases $=12 \%)$ \\
5 & Yes: 628 cases $=65 \% ;$ No: 338 cases $=35 \%$ \\
6 & Economic: 406 cases $=42 \%$ \\
& Sociodemographic: 338 cases $=35 \%$ \\
& Geographic and environmental: 155 cases $=16 \%$ \\
& Government and justice management: 48 cases $=5 \%$ \\
7 & Other: 19 cases $=2 \%$ \\
& Yes: 937 cases $=97 \% ;$ No: 29 cases $=3 \%$ \\
& Yes: 840 cases $=87 \% ;$ No: 126 cases $=13 \%$ \\
& Mean $=5.3$ \\
& Most frequent: Simplify the classification of themes \\
& Yes: 502 cases $=52 \% ;$ No: 464 cases $=48 \%$ \\
\hline &
\end{tabular}

- It is remarkable that the most preferred means to gather official information is through Android apps (smartphones and tablets); some years ago the PC-Internet platform was the most utilized. This can be answered in several ways, one of them being found in [15] where some plausible scenarios in the complex interplay of the Internet and new emerging technologies like Android apps is discussed.

- INEGI is one of the most frequented bureaus to gather official information, along with the Ministry of Economy, but it was somewhat surprising that the Ministry of Labor and Social Welfare took third place as an information source (perhaps due to the unemployment data that the office produces).

- It is important to notice that although students' level of credibility of government information is low (item 11 , with a $52 \%$ credibility score), students have huge confidence in INEGI (item 7 , with $97 \%$ ).

Now, we present some cross tabulations in order to increase the information derived from the statistical analysis. In Table 3 is shown the frequency of consulting official information per academic subject. As was established previously, economic, financial and research methods were the most prevalent assignments, but it is also interesting that demography, environment and biology subjects are also consulted frequently.

Another interesting cross tabulation is between items 7 and 9, i.e., the credibility of the INEGI information against the ease of use of its website. In Table 4 is shown the interesting fact that despite the mean being almost 5.3 (approximately in the middle), there is a non-trivial number of students (261 in the 6 value of ease of use and 123 in the 7 value of that variable) showing a potential correlation between the ease of use of the INEGI website and its credibility among students (and perhaps, among the general population).

A final cross tabulation we want to present is shown in Table 5. Here we match item 9, ease of use of INEGI information, against the most problematic areas to improve in the INEGI website. Here we note as an interesting fact, that no student considered that the information on the INEGI website has a 0 (most difficult) nor a 10 (easiest) value. Moreover, it is important to note that the statistical devices or tools (denoted in the column title as "4") have a relatively low demand among students. This could be explained by two factors: that the statistical tools themselves are enough and sufficient as they are provided on the INEGI website, or that there is no need for sophisticated methods of multivariate statistics, time series analysis or related tools.

\section{Final remarks}

Official statistics are of fundamental importance in understanding the important facts about economic, sociodemographic, geographic, environmental and governmental management in a country. However, as has been shown in this work, in general terms and despite Mexican government efforts, the official information does not have too much credibility among undergraduate students, though the information produced by INEGI does. That is, despite being a governmentsupported organization, INEGI has remarkable credibility among undergraduate students as was shown in the results of survey item number 7 . However, it is also true that the general impression students have about accessing information on the INEGI website is that data is difficult to access. This could be a consequence of the enormous amount of data derived from the several official statistics projects developed by INEGI.

Based on our own experience, i.e., not derived directly from the results of this study, but with certain 
Table 3

Cross tabulation of frequency of consulting government information (item 1) against academic subjects consulted (item 2)

\begin{tabular}{|c|c|c|c|c|c|c|c|c|}
\hline \multicolumn{9}{|c|}{ Item 2} \\
\hline Item 1 & Biology & Demography & Economics & Engineering & Environment & Finance & Quatitative methods & Research methods \\
\hline 0 & 1 & 1 & 28 & 2 & 0 & 11 & 0 & 5 \\
\hline 1 & 3 & 7 & 130 & 2 & 15 & 28 & 3 & 15 \\
\hline 2 & 10 & 30 & 426 & 6 & 23 & 119 & 8 & 54 \\
\hline 3 & 0 & 1 & 5 & 0 & 1 & 0 & 0 & 0 \\
\hline 4 & 0 & 1 & 5 & 0 & 0 & 3 & 0 & 1 \\
\hline 5 & 0 & 0 & 3 & 0 & 1 & 1 & 0 & 0 \\
\hline 6 & 0 & 0 & 4 & 0 & 0 & 1 & 0 & 1 \\
\hline 7 & 1 & 0 & 7 & 0 & 0 & 1 & 0 & 0 \\
\hline 8 & 0 & 0 & 1 & 0 & 0 & 0 & 0 & 1 \\
\hline
\end{tabular}

Table 4

Cross tabulation of credibility of INEGI information (item 7) and the ease of use its website (item 9)

\begin{tabular}{ccccccccc}
\hline \multicolumn{8}{c}{ Item 9} \\
\hline Item 7 & 2 & 3 & 4 & 5 & 6 & 7 & 8 & 9 \\
\hline 1 & 2 & 36 & 178 & 328 & 261 & 123 & 8 & 1 \\
2 & 0 & 0 & 8 & 8 & 9 & 4 & 0 & 0 \\
\hline
\end{tabular}

Table 5

Cross tabulation of ease of use of INEGI information (item 9) and themes to be simplified on the INEGI website (item10)

\begin{tabular}{cccccc}
\hline \multicolumn{7}{c}{ Item 10} & & \\
\hline Item 9 & 1 & 2 & 3 & 4 & 5 \\
\hline 2 & 1 & 1 & 0 & 0 & 0 \\
3 & 0 & 20 & 8 & 0 & 8 \\
4 & 1 & 102 & 39 & 4 & 40 \\
5 & 9 & 173 & 78 & 5 & 71 \\
6 & 6 & 133 & 62 & 9 & 60 \\
7 & 3 & 66 & 33 & 1 & 24 \\
8 & 0 & 6 & 2 & 0 & 0 \\
9 & 0 & 1 & 0 & 0 & 0 \\
\hline
\end{tabular}

reasonability due our practice, we claim that this fact could be due to a Constitutional Reform in Mexico, in 2008, when INEGI changed its government status to an autonomous organization with financial and technical autonomy. That is, by this split of the Mexican government, society in general was prone to increase its confidence in INEGI's information, especially in government data such as the inflation rate and unemployment.

According to our experience, this problem could be lessened, at least to some degree, by favoring more intimate contact between the official statistics offices and academia. This could be promoted by offering academic lectures - delivered for example by official seniors of INEGI and other ministries - that provide insight and advice on the use of official statistics. Another way of promoting this contact could be by fostering MSc and $\mathrm{PhD}$ studies in statistics among the personnel of the NSO in well-recognized academic institutions. Finally, and this could be the most difficult problem to solve, the NSO should seriously think about how to simplify the way official statistics are presented to the general population, in order to make access easier for students and general users of official statistics.

As has been said before, we recognize that this is a complex issue, and this article tries to give a first insight, in the Mexican context, to study, analyze and try to solve this academic-official connection.

\section{References}

[1] Ho FH. The Role of Statistical Agencies in the Promotion of Statistical Literacy Among Students. Paper presented at 55th meeting of the International Statistical Institute; 2005; Sidney. Available from: http://iase-web.org/documents/papers/isi55/ Ho.pdf.

[2] Heath J. What the indicators indicate [Lo que indican los indicadores]. Mexico: National Institute of Statistics and Geography; 2011: 419. Available from: http://internet.contenidos. inegi.org.mx/contenidos/productos//prod_serv/contenidos/ espanol/bvinegi/productos/estudios/indican_indi/indica_v25 iv12.pdf.

[3] National Institute of Statistics and Geography. Count me [Cuéntame] [Internet]. Mexico: INEGI; 2013. Available from: http://cuentame.inegi.org.mx/juegos/default.aspx?tema=J.

[4] Moore DS and Notz WI. Statistics: Concepts and Controversies. 7th ed. New York: W.H. Freeman; 2007: 561.

[5] Paulos JA. Innumeracy: Mathematical Illiteracy and Its Consequences. New York: Vintage Books; 1990: 180.

[6] Gaissmaier W, Gigerenzer G. Statistical illiteracy undermines informed shared decision making. Z Evid Fortbild Qual Gesundhwes. 2008; 102(7): 411-3.

[7] Silva JLAR. Probability and statistics in legal issues [Probabilidad y estadística en situaciones legales]. Ciencia UANL. 2014; 17(68): 8-12. Available from: http://cienciauanl.uanl. $\mathrm{mx} / \mathrm{p}=1937$.

[8] Pullinger J. Statistics making an impact. J. R. Statist. Soc. A. 2013; 176(Part 4): 819-839. Available from: http://www.rss. org.uk/Images/PDF/publications/rss-presidents-addressjohn-pullinger-2013.pdf.

[9] Depoutot R. Co-operation between official and academic statisticians: the seasonal adjustment project of the European Statistical System. In: Bulletin of the International Statistical Institute. Proceedings of the 52nd session. Tome LVIII; 1999; Finland. Available from: http://www.stat.fi/isi99/proceedings/ arkisto/varasto/depo1025.pdf. 
[10] Silva JLAR. Comparative analysis of the fitting classical theory against the extreme value theory in the maximum income distribution [Análisis comparativo de la teoría clásica de ajustes con respecto a la teoría de valores extremos en la distribución de los máximos de los ingresos]. Boletín del Sistema Nacional de Información Estadística y Geográfica. 2009; 2(2): 30-53. Available from: https://goo.gl/g1FrNg.

[11] Saporta G. The unexploited mines of academic and official statistics. In: Academic and Official Statistics Cooperation. Proceedings of the Seminar on Academic and Of ficial Statistics cooperation held in Bucharest in September 1998; Italy: Eurostat; 1998. pp. 11-15. Available from: http://cedric.cnam.fr/ saporta/AOSC3.pdf.

[12] Nathan G. Cooperation between a bureau and an academic department of statistics as a basis for teaching official statistics. In: Proceedings of the 56th Session of the International Statistical Institute; 2007; Lisbon. Available at: http://iaseweb.org/documents/papers/isi56/IPM43_Nathan.pdf.

[13] Weldon KL. Statistical education with official statistics and the Internet. Paper presented at 53rd meeting of the International Statistical Institute; 2001; Seoul. Available from: https://iase-web.org/documents/papers/isi53/844.pdf.

[14] Stockwell EG. Some problems concerning the use of official statistics in sociological research. Milbank Mem Fund Q, 1965; 43(1): 10-16.

[15] de Mooij M. Media behavior and culture. In: Human and Mediated Communication around the World. Cham: Springer; 2014. p. $243-279$

\section{Appendix}

Questionnaire designed to gather information about the students' habits, attitudes and confidence about official information.

1. How many times during your academic semester do you consult government Internet websites to obtain information?

$\square 0 ; \square 1 ; \square 2 ; \square 3 ; \square 4 ; \square 5 ; \square 6 ; \square 7 ;$

$\square 8$ or more, please specify:

2. If any, what is the subject of your assignment( $s)$ where you were requested to consult official or governmental information during your previous semester?

(1) Assignment 1:

(2) Assignment 2:

(3) Assignment 3:

3. Which of the following do you use to carry out your consultation?

(1) $\square$ Internet; (2) $\square$ Specialized consulting centers; (3) $\square$ Android apps; (4) $\square$ Mac/OS apps; (5)

$\square$ Public libraries; (6) $\square$ Journals;

(7) $\square$ Windows-based apps; (8) $\square$ Newspapers;

(9) $\square$ Books; (10) $\square$ News (TV, radio, etc.)

(11) $\square$ Other. Please specify:
4. List, in order of frequency, the name of the ministries you have consulted.

(1) $\square$ National Institute of Statistics and Geography (INEGI).

(2) $\square$ Ministry of Energy.

(3) $\square$ Ministry of State.

(4) $\square$ Ministry of Foreign Affairs.

(5) $\square$ National Defense.

(6) $\square$ Marines.

(7) $\square$ Ministry of Finance.

(8) $\square$ Ministry of Social Development.

(9) $\square$ Ministry of Environment and Natural Resources.

(10) $\square$ Ministry of Energy.

(11) $\square$ Ministry of Economy.

(12) $\square$ Ministry of Education.

(13) $\square$ Ministry of Agriculture, Livestock, Fishing and Food.

(14) $\square$ Ministry of Communications and Transportation.

(15) $\square$ Ministry of Public Function.

(16) $\square$ Ministry of Health.

(17) $\square$ Labor and Social Welfare.

(18) $\square$ Ministry of Agricultural, Territorial and Urban Development.

(19) $\square$ Ministry of Tourism.

(20) $\square$ Legal Council of the Federal Executive.

(21) $\square$ General Attorney of the Republic.

(22) $\square$ Bank of Mexico.

(23) $\square$ State Governments.

(24) $\square$ Municipal Governments.

(25) $\square$ Other. Please specify:

5. Have you consulted the INEGI website during the last six months?

(1) $\square$ Yes; (2) $\square$ No (Go to question 7).

6. What is the kind of information you have consulted on the INEGI website? (Please just mark one, the most frequent you've consulted.)

(1) $\square$ Economic

(2) $\square$ Sociodemographic

(3) $\square$ Geographic and environmental

(4) $\square$ Government and justice management

(5) $\square$ Other. Please specify:

7. Do you consider that the INEGI information has credibility?

(1) $\square$ Yes; (2) $\square$ No.

8. Do you consider that the information is reasonably up-to-date on the INEGI website?

(1) $\square$ Yes; (2) $\square$ No.

9. In a scale from 0 (most difficult) to 10 (easiest), how easy to use do you consider the INEGI Internet website to be? 
Answer:

10. If any, what would be the main action you would recommend in order to increase the ease-of-use level of the INEGI website?

(1) $\square$ None. It seems to me everything is fine with the INEGI page.

(2) $\square$ Simplify the classification of themes.

(3) $\square$ Promote the use of more graphical devices.
(4) $\square$ Promote the use of application of more statistical tools.

(5) $\square$ Promote the use of application of more geographic information systems tools.

(6) $\square$ Other. Please, specify:

11. Do you consider that the official information of the Mexican government has credibility? (1) $\square$ Yes; (2) $\square$ No. 